\title{
Analisis Nilai-Nilai Religius Pada Novel Bumi Cinta Karya Habiburrahman El-shirazy
}

\section{Analysis of Religious Values in the Novel Bumi Cinta Create of Habiburrahman El-shirazy}

\author{
Sri Yanti (1) \& Hanina ${ }^{(2) *}$ \\ Fakultas Keguruan dan Ilmu Pendidikan, Universitas Asahan, Indonesia
}

Disubmit: 13 Oktober 2020; Diproses: 14 Oktober 2020; Diaccept: 16 November 2020; Dipublish: 01 Desember 2020 *Corresponding author: E-mail: haninaninatanjung@gmail.com

\begin{abstract}
Abstrak
Penelitian ini bertujuan untuk mendeskripsikan nilai religius novel "Bumi Cinta" karya Habiburrahman El-Shirazy. Untuk mengetahui nilai-nilai religius menggunakan metode deskriftif kualitatif. Objek dalam penelitian ini adalah nilai-nilai religius dalam novel Bumi Cinta Karya Habiburrahman El-Shirazy, Sumber data yang di pakai menggunakan sumber data primer dan sumber data sekunder dengan teknik pengumpulan data yaitu teknik pustaka dan teknik catat dan teknik analisis data yang di gunakan adalah membaca berulang-ulang novel, menghayati, memahami, mengumpulkan data, dan menggaris bawahi, mendeskripsikan dan menyimpulkan hasil penelitian. Hasil penelitian ini dapat menjawab dari pernyataan penelitian yaitu terdapat terdapat nilai-nilai religius (akidah, syariah dan akhlak) dalam novel Bumi Cinta Karya Habiburrahman El-Shirazy. Nilai akidah dapat di lihat dari keyakinan dan kepercayaan tokoh kepada Allah Swt. Yang maha pencipta dan maha segala nya. Nilai syariah dapat di lihat dari para tokoh yang mematuhi perintah-perintah Allah Swt menjauhi segala larangan nya. Nilai akhlak dapat di lihat dari sifat para tokoh kepada Allah Swt, Rasulullah Saw, sesama manusia, dan lingkungan.
\end{abstract}

Kata Kunci: Nilai-Nilai Religius; Novel Bumi Cinta

\begin{abstract}
This study aims to describe the religious value of the novel "Bumi Cinta" by Habiburrahman El-Shirazy. To find out religious values using qualitative descriptive methods. The object of this research is the religious values in the novel Bumi Cinta Karya Habiburrahman El-Shirazy. read the novel over and over again, appreciate, understand, collect data, and underline, describe and conclude the research results. The results of this study can answer from the research statement that there are religious values (faith, sharia and morals) in the novel Bumi Cinta Karya Habiburrahman El-Shirazy. The value of faith can be seen from the beliefs and beliefs of figures in Allah SWT. The creator and all. The value of sharia can be seen from the characters who obey the commands of Allah SWT stay away from all its prohibitions. Moral values can be seen from the character of the characters to Allah SWT, Rasulullah Saw, fellow human beings, and the environment.
\end{abstract}

Keywords: Religious Value; Novel Bumi Cinta

\section{Rekomendasi mensitasi:}

Yanti, S., \& Hanina, 2020. Analisis Nilai-Nilai Religius Pada Novel Bumi Cinta Karya Habiburrahman Elshirazy. Jurnal Penelitian Pendidikan, Psikologi dan Kesehatan (J-P3K), 1(3): 201-210. 


\section{PENDAHULUAN}

Karya sastra adalah ciptaan yang disampaikan dengan komunikatif tentang maksud penelitian penulis untuk tujuan estetika. Kehidupan dan realitas yang ada dalam karya sastra memiliki cakupan hubungan antara manusia dengan keadaan sosial yang menjadi inspirasi penciptaan. Kemunculan karya sastra dalam kehidupan manusia juga sangat membutuhkan pemikiran yang tinggi bagi penikmatnya, sebab karya sastra akan menimbulkan beraneka ragam ide-ide dan menuntut penikmat karya sastra tersebut untuk berfikir lagi dan lagi. Sastra diciptakan oleh sastrawan untuk dinikmati, dihayati, dipahami, dan dimanfaatkan oleh pembaca atau penikmat.

Menurut Sumardjo (2013), "Karya sastra adalah ungkapan pribadi manusia yang beberapa pengalaman, pemikiran, perasan ide, dan semangat keyakinan dalam suatu bentuk gambaran konkrit yang membangkitkan pesona dengan alat bahasa". Menurut Junus (Siswanto, 2008), "Karya sastra lahir dari sebuah renungan seorang sastrawan yang ingin mengungkapkan apa yang di pikirkannya tentang pandangan dunia pada umumnya".

Menurut Horace (Ismawati, 2013), "Bahwa sastra itu dulce et utile, artinya indah dan bermakna berarti di dalam karya sastra tersebut terdapat nilai-nilai yang dapat dijadikan sebagai bahan pembelajaran oleh pembaca. Selain itu karena bermakna sastra juga berfungsi sebagai bahan renungan dan refleksi kehidupan karena sastra bersifat koeksistensi (berdampingan) dengan kehidupan".
Berdasarkan pendapat ahli di atas, karya sastra dapat digunakan sebagai alat untuk mengkomunikasikan perasaan dan isi hati pengarang. Karya sastra lahir dan tidak bisa dilepaskan dari pengarangnya. Dan sebaliknya, pengarang pun tidak bisa pula terlepas dari keadaan dan kenyataan yang ada disekitarnya, untuk mengetahui hal itu kita perlu menelaah karya sastra tersebut.

Sebelum menelaah sebuah karya sasta terlebih dahulu kita membaca karya sastra tersebut. Menurut Hodgsun (Tarigan, 2005), "Membaca mempunyai peranan sosial yang sangat penting dalam kehidupan manusia sepanjang masa, karena membaca merupakan suatu alat komunikasi yang sangat di perlukan dalam suatu masyarakat berbudaya. Selain itu membaca merupakan suatu daya pemersatu yang ampuh dan cenderung mempersatukan kelompokkelompok sosial dengan memberikan pengalaman-pengalaman umum seolah di alami sendiri dan dengan menanamkan sikap, ide, minat dan aspirasi umum.

Kegiatan membaca merupakan kegiatan menggunakan berbagai keterampilan, yaitu kegiatan mengamati, memahami, dan memikirkan yang dapat menumbuhkan pandangan dan sikap serta tindakan-tindakan positif terhadap diri pembacanya. Membaca bukanlah suatu kegiatan yang sederhana. Membaca dapat dilakukan dengan berbagai cara seperti membaca diam, membaca nyaring, membaca telaah isi, membaca telaah bahasa, membaca kritis, membaca pemahaman juga terdapat hal-hal yang mempengaruhi keberhasilan kemampuan siswa dalam membaca. 
Semua karya sastra memilik manfaat bagi manusia yang di peroleh melalui dua aspek, yaitu estetika dan etika. Yang secara keseluruhan ditujukan kepada kepuasan rohani. Kualitas estekia yang membangkitkan kegairahan hidup, rasa cinta, setia, dan cemburu termasuk semangat intelektual dan perjuangan. Kualitas etis, yaitu masalah-masalah moral. Konservasi sosial tidak sematamata diperoleh melalui agama, kekuatan hukum dan adat istiadat, norma dan aturan, tetapi juga melalui sistem simbol bahasa.

Sastra tidak hanya sebuah imajinasi yang dapat di nikmati, tetapi bisa di pelajari mengenai sosiologi psikologi, adat istiadat, moral, budi pekerti, agama, tutunan masyarakat dan tingkah laku manusia di suatu masa. Melalui karya sastra, seorang pengarang menyampaikan pandangannya tentang kehidupan yang ada di sekitarnya. Mengapresiasi karya sastra berarti kita berusaha menemukan nilai-nilai kehidupan yang tercermin dalam karya satra. Nilai-nilai kehidupan masyarakat yang bisa di temukan dalam karya sastra seperti: sosial, budaya, religius, moral, dan intrinsik.

Bentuk bentuk karya sastra sangatlah beragam mulai dari puisi, prosa dan drama. Puisi, prosa, dan drama juga memiliki berbagai macam jenis yaitu puisi lama, puisi baru, puisi bebas, dan puisi kontemporer. Kemudian jenis-jenis prosa yaitu roman, cerita pendek (cerpen), dan novel. Dan jenis jenis drama yaitu drama tragedi, drama komedi, dan drama musikal. Namun yang akan menjadi pilihan peneliti untuk di analisis adalah novel.
Novel adalah karangan prosa yang panjang mengandung rangkaian cerita kehidupan seseorang di sekitarnya. Demikian juga novel "Bumi Cinta" karya Habiburrahman El-Shirazy menceritakan tentang bagaimana seorang muslim beriman seharusnya meraih kemenangan yang Allah janjikan melalui usaha kerasnya. Menghadapi musuh musuh iman yang begitu besar.

Novel "Bumi Cinta" karya Habiburrahman El-Shirazy kita di ajak untuk ikut kembali memperoleh pelajaran hidup dari seorang pemuda Muhammad Ayyas yang kerap di panggil Ayyas ini adalah seorang mahasiswa dari Indonesia yang juga seorang santri salaf. Yang harus melakukan sebuah penelitian di negeri yang paling menjunjung tinggi seks bebas "free sex" yaitu Rusia. Ia harus berjuang mempertahankan keimanan, keyakinan dan akidahnya yang tidak tangungtanggung level godaannya. Tinggal 1 apartemen bersama 2 gadis cantik bernama linor agen Israel dan Yelena pelacur Moskawa. Meskipun begitu, tidak pernah Ayyas tergoda dan terkalahkan iman nya oleh kecantikan mereka.

Karya sastra memberikan pesan moral yang berwujud nilai religius. Nilai yang sangat mempengaruhi perilaku dan tindakan manusia baik yang dilakukan sercara pribadi maupun kelompok. Dengan adanya religius dapat memberikan kesadaran terhadap pembaca untuk berbuat baik.

Religius adalah suatu keterikatan terhadap suatu keyakinan seseorang terhadap agama yang dianutnya serta aktivitas keyakinan melalui norma-norma atau agama yang di percayainya secara konsisten antara pikiran, perasaan dan 
perilakunya. Bukan hanya yang berkaitan dengan aktivitas yang tampak dan dapat di lihat mata, tapi juga aktivitas yang tampak dan terjadi dalam hati seseorang. Dalam novel "Bumi Cinta" karya Habiburrahman El Shirazy di temukan nilai-nilai religiusitas yaitu nilai keyakinan (aqidah), norma atau hukum (syariah) dan perilaku (akhlak).

Berdasarkan pemaparan di atas, peneliti ingin mengetahui lebih dalam mengenai nilai- nilai religius. Subjek yang peneliti ambil yaitu tentang akidah, syariat dan akhlak. Peneliti tertarik untuk meneliti nilai nilai religiusitas/religius (akidah, syariat dan akhlak). Dalam novel yang berjudul "Bumi Cinta Karya Habiburahman El-Shirazy". Penggunaan bahasa dan isi pada novel tersebut lebih menekankan pada nilai-nilai kandungan Islam yang bersifat religi.

\section{METODE PENELITIAN}

Penelitian ini tidak terikat tempat penelitian karena objek yang di kaji berupa naskah (teks) sastra, yaitu novel "Bumi Cinta" Karya Habiburrahman ElShirazy. Penelitian ini merupakan penelitian kepustakaan sehingga memerlukan bahan pustaka sebagai bahan referensi yang banyak didapatkan di perputakaan. Penelitian ini mulai dilaksanakan pada bulan Mei 2020.

Penelitian ini menggunakan pendekatan kualitatif dan jenis metode deskriptif kualitatif. Penelitian kualitatif yaitu penelitian yang berlandasan pada filsafat post positivisme, digunakan untuk meneliti pada kondisi obyek yang alamiah, dimana peneliti adalah sebagai instrumen kunci, pengambilan sampel dan sumber data (Sugiyono, 2016).
Metode penelitian deskriptif kualitatif, artinya yang di analisis dan hasil analisisnya berbentuk deskripsi, dengan data yang di kumpulkan berupa kata-kata, gambaran dan bukan angka-angka (Iskandar, 2009).

Data dalam penelitian ini di bagi menjadi dua, yaitu data primer dan data sekunder.

Data primer dalam penelitian ini adalah asli. Dalam hal ini data diperoleh secara langsung dari objek penelitian yaitu nilai-nilai religius dalam novel "Bumi Cinta" karya Habiburrahman El-Shirazy. Data primernya adalah keseluruhan teks Novel Bumi Cinta Karya Habiburrahman El-Shirazy yang berjumlah 546 halaman (Shirazy, 2019).

Data sekunder adalah data sebagai penunjang penelitian. Data sekuder merupakan data penelitian yang di peroleh peneliti secara tidak langsung melalui media perantara. Seperti: bukubuku, dokumentasi, sumber penelitian novel, dan jurnal sastra yaitu, Putri (2018) dengan judul, "Nilai Religiusitas dalam Novel Tasbih Cinta di Langit Moskow Karya Indah El-Hafidz". Dan sumber data penelitian ini adalah novel Bumi Cinta Karya Habiburrahman El-Shirazy yang di terbitkan oleh Republika berjumlah 546 halaman.

Arikunto (2013) menyatakan bahwa, alat yang digunakan oleh peneliti dalam mengumpulkan data agar pekerjaannya lebih mudah dan lebih baik dalam arti lebih cermat. Dalam penelitian ini peneliti membutuhkan data tentang nilai-nilai religiusitas (akidah, syariat, dan akhlak) dalam novel "bumi cinta" karya habiburrahman El-Shirazy. Data di dapatkan dari pedoman dokumentasi 
dengan cara penabelan dan di tambah dengan keterangan sehingga mempermudah dalam memperoses data.

Adapun tabel yang digunakan adalah sebagai berikut:

Tabel 1. Religiusitas/religius novel "Bumi Cinta" karya Habiburrahman El-Shirazy.

\begin{tabular}{llll}
\hline No & $\begin{array}{l}\text { Nilai } \\
\text { religiusitas }\end{array}$ & Deskripsi & Halaman \\
\hline 1 & Akidah & & \\
2 & Syariat & & \\
3 & Akhlak & & \\
\hline
\end{tabular}

Menurut Bogdan dan Biklen (Moleong, 2012) "Analisis data adalah upaya yang dilakukan dengan jalan bekerja dengan data, mengorganisasikan data, memilah data menjadi satuan yang yang dapat di kelola, mensintesiskannya mencari dan menemukan pola, menemukan apa yang penting dan apa yang di pelajari serta memutuskan apa yang dapat di ceritakan kepada orang lain".

Data yang di peroleh dengan membaca dan memahami nilai religiusitas (akidah, syariat dan akhlak). Dalam novel "Bumi Cinta" Karya Habiburrahman ElShirazy. Peneliti juga menggunakan kajian pustaka untuk melengkapi data yaitu membaca buku-buku yang ada hubungan nya dengan objek penelitian.

Langkah-langkah yang di lakukan setelah data di peroleh yaitu sebagai berikut:

1. Membaca berulang-ulang dengan cermat, mengahayati, dan memahami isi novel "Bumi Cinta" Karya Habiburrahman El-Shirazy.

2. Mengumpulkan dari isi cerita isi novel "Bumi Cinta" Karya Habiburrahman ElShirazy yang berhubungan dengan nilai religius ( akidah,syariat, dan akhlak).
3. Menggaris bawahi pada isi cerita yang berhubungan dengan nilai religius yang

4. mencakup akidah, syariat, dan akhlak dalam novel "Bumi Cinta" Karya Habiburrahman El-Shirazy.

5. Mendeskripsikan hasil temuan peneliti yang berhubungan dengan nilai religius yang mencakup akidah, syariah, dan akhlak dalam novel "Bumi Cinta" Karya Habiburrahman El-Shirazy.

6. Menyimpulkan hasil penelitian.

\section{HASIL DAN PEMBAHANSAN}

Berikut adalah deskripsi data penelitian yang berkaitan dengan nilai religiusitas/religius (akidah, syariat, dan akhlak) dalam novel "Bumi Cinta Karya Habiburrahman El-Shirazy.

\section{Religius Novel Bumi Cinta Karya Habiburrahman El-Shirazy.}

Religius adalah salah satu cara pandang seseorang mengenai agamanya serta bagaimana orang tersebut menggunakan keyakinan dalam agamanya. Religi tersebut suatu keyakinan nilai-nilai, dan norma yang harus di jaga agar jangan sampai menyimpang. Adapun nilai-nilai religius pada novel "Bumi Cinta Karya Habiburrahman El-Shirazy" yaitu, akidah, syariah, dan akhlak.

Berikut analisis data nilai-nilai religius pada novel Bumi Cinta Karya Habiburrahman El-Shirazy yang di uraikan:

\section{Akidah}

Adalah suatu bentuk pengakuan atau persaksian secara sadar mengenai keyakinan, keimanan, kepercayaan bahwa ada suatu zat yang esa yang maha kuasa 
yang hanya kepadanya bergantung segala sesuatu. Tokoh utama dalam novel "Bumi Cinta Karya Habiburrahman El-Shirazy" yaitu, Muhammad Ayyas atau di panggil Ayyas tokoh yang berkeyakinan bahwasanya Allah adalah Tuhan yang maha berkehendak. Segala sesuatu yang terjadi di dunia ini pasti karena allah yang mengkehedakinya sehingga Ayyas terus mengingat Allah dalam setiap langkahnya seperti kutipan di bawah ini:

"Ya Allah rahmatilah hamba mu ini dengan meninggalkan maksiat selamanya, selama hamba mu yang lemah ini engkau beri hidup di dunia ini". (Halaman 40).

"Kalau Tuhan berkendak apa pun bisa terjadi" sahut Ayyas. (Halaman 62).

"Ayyas membaca istifar, salah menyangka pada perempuan tua berkerudung kozinka putih itu". (Halaman 62).

"Duhai Allah, jauhkan hamba mu dari kejahatan dan fitrah yang di timbulkan oleh wajah jelita noniknonik muda Rusia".

"Mudah insya Allah", lirihnya dalam hati. (Halaman 81).

Kemudian tokoh dalam novel "Bumi Cinta Karya Habiburrahman El- Shirazy" berkeyakinan bahwa janji-janji yang dibuat itu jika Allah berkehendak maka janji tersebut dapat di tepatinya dan selalu mengucapkan kata insya Allah jika ingin berjanji seperti kutipan tersebut:

"Insya Allah tulang yang lepas dari engselnya sudah kembali seperti sedia kala hanya beberapa otot perlu sedikit saya sentuh lagi", gumam pak Joko sambil mengurut bagian-bagian tertentu di pundak kiri Ayyas, (Halaman 140).

"Ya nanti kalau cukup waktu dan cukup biaya saya akan mengunjungi tiga kota insya Allah", (Halaman 363).

"Insya Allah", tukas Yelena dan Devid hampir bersamaan.

"Eh, kau jadi pulang dua hari lagi, Yas?, tanya Devid".

"Ya insya Allah, makanya hari ini kesempatkan untuk melihat Kremlin. (Halaman 516).

Para tokoh tidak hanya mengucapkan kalimat baik saat berjanji, tetapi juga menggunakan kalimat alhamdulillah saat mendengar kabar baik. Tokoh percaya kabar baik itu datangnya dari Allah seperti kutipan di bawah ini:
"Alhamdulillah, selama di pesantrenkan setiap hari pakai bahasa arab, jadi aku cukup lancar berkomunikasi dengan ulama itu". (Halaman 20)
"Jadi kamu pernah kuliah di Madinah"?

"Iya imam", jawab Ayyas.

"Alhamdulillah, pernah belajar pada Syaikh Abu Bakar AlJazairy"?

"Allhamdulillah pernah imam. (Halaman 109)

"Alhamdulillah, Yelena sekarang juga sudah muslimah". 
“Benarkah?”, Linor tidak percaya.

"Benar".

"Yelena yang tidak percaya adanya tuhan sekarang muslimah"

"Iya mengucapakan kaliamat syahadat di masjid prospek mira. Ribuan orang menjadi saksi keislamannya", (Halaman 538).

Kutipan ini juga menjelaskan bahwa tokoh yakin dan percaya bahwa segala sesuatu yang terjadi kehendak Allah dan semua umat suatu saat akan kembali kepadanya, seperti kutipan di bawah ini:

\section{"Inna lillahi, Ayyas mengucap dalam hati, ia merasa belum sampai ke Moskwa pun ia sudah terjerat oleh fitrah kecantikan nonik muda Rusia", (Halaman 23). \\ "Innalillah" seru Ayyas". \\ "Kamu jangan kaget. Di sini banyak yang tidak beragama", (Halaman 51). \\ "Kalau tuhan berkendak apa pun bisa terjadi" sahut Ayyas, (Halaman 62).}

\section{Syariat}

Syariat adalah norma hukum dasar yang di wahyukan Allah yang wajib di ikuti oleh orang Islam, baik dengan berhubungan dengan sesama manusia dan benda dalam masyarakat. Dalam beragama, keyakinan kepada Tuhan yaitu menjalankan perintah yang telah di tetapkan dalam Al- Quran dan As-Sunah agar mendapat balasan kesenangan baik di dunia maupun di akhirat. Seperti perintah menjalankan shalat, membaca AlQuran, menunaikan ibadah haji, dan ibadah lainnya baik wajib maupun sunah. Seperti kutipan di bawah ini:

"Ayyas menutup pintu kamarnya, menyalakan lampu kamar mandi, dan mengambil air wudhu ia langsung shalat menghadap selatan". (Halaman 39)

"Selesai berdoa Ayyas kembali tegak mendirikan shalat zuhur dan ashar, jamak dan qashar". (Halaman 41)

"Yelena sampai di apartemen, ketika Ayyas sedang shalat. Suara Ayyas membaca Al-Quran ketika shalat terdengar jelas". (Halaman 49)

"Selesai shalat shubuh seperti biasa ia membaca Al-Quran, zikir mat'tsurat pagi, dan membaca kitab mudzakarat fi manazil ashshiddiqin wa ar-rabbaniyyin, yang merupakan penjelas dari kalimat penuh cahaya dari ibnu athaillah as sakandary". (Halaman 58)

"Maafkan saya Doktor, tadi saya tidak menjawab ketika anda menyapa saya. Sebab saya seperti yang mungkin sudah Doktor ketahui sedang melakukan shalat beribadah seperti yang di ajarkan oleh agama saya, Islam", (Halaman 200).

"Hari ini saya puasa bibi", jawab Ayyas.

"O puji tuhan, kau orang yang taat agama"., (Halaman 226).

"Usai shalat shubuh seperti biasa, ia membaca Al-Quran, zikir pagi, dan kali ini membaca kitab kecil 
tipis berjudul "Nahwal Ma' aali", (Halaman 324).

"Mungkin aku harus kembali shalat agar jiwa $k u$ tidak kerontang",gumam Devid. Shalat memang salah satu nutrisi jiwa paling penting, sahut Ayyas, (Halaman 482).

\section{Akhlak}

Adalah peraturan Allah yang bersumberkan pada Al-Quran dan Sunah Rasul, baik yang menyangkut hubungan dengan Allah, hubungan manusia dengan manusia, hubungan manusia dengan lingkungan karena akhlak meresap dalam jiwa. Akhlak yang baik yaitu patuh dan taat terhadap orang tua, peduli terhadap orang lain, dan saling menghormati dan menghargai saling membantu dan lain lain. Seperti kutipan di bawah ini:

"Devid tersenyum melihat sahabat nya itu tertidur lelap, Devid mengambil selimut di almari lalu menyelimutkan ke tubuh Ayyas". (Halaman 41)

"Tahu rutenya".

"Belum, nanti tanya sama orang".

"Kalau pertama ke Moskawa masih tetap bingung. Atau aku temani saja hari ini aku msuk kerja sore, bagaiamana?", (Halaman 60).

"Yelena meletakkan tas nya di kamar lalu keluar lagi, mengambil sapu dan berusaha membersihkan kaca yang berhamburan. Ayyas bangkit, ia merasa harus membantu Yelena dengan berjongkok ia memunguti serpihan botol yang pecah bercampur darah yang berceceran di lantai yang di lapisi karpet kayu yang mengkilat itu", (Halaman124)

"Ya sudah, tapi saya sarankan mas Ayyas tidak usah cari perkara dengan orang Rusia lagi ya”.

"Iya pak, baik", (Halaman 140).

"Oo jiwa menolong anda mengagumkan. Di india kau menyelamatkan putri ku. Dan kini kau membawa perempuan yang tak berdaya yang hampir mati ke rumah sakit. Tapi kau harus hatihati kalau mau menolong seseorang, jangan sampai kau tulus menolong seseorang tapi justru kecelakaan yang kau hadapi. Saya tidak tahu seperti apa nanti polisi akan menangani kasus perempuan tak berdaya ini. Semoga kau tidak kena getah mencelakan kamu", (Halaman 184)

"Sejak itu Ayyas dekat dengan mereka berdua Shamil dan Sarah sangat antusias mendengar penjelasan Ayyas tentang islam. Mereka berdua sangat bersemangat belajar membaca AlQuran kepada Ayyas. Aliyev sangat senang kedua cucunya bisa belajar dengan tanpa membayar sepeser pun kepada Ayyas". (Halaman 477).

Dari kutipan di atas dapat di lihat akhlak berupa saling tolong menolong dan peduli terhadap sesama manusia. 


\section{SIMPULAN}

Berdasarkan penelitan yang telah dilakukan mengenai nilai-nilai religius pada novel Bumi Cinta karya Habiburrahman El-Shirazy. Maka dapat di tarik kesimpulan yaitu:

1. Novel bumi cinta karya Habiburrahman El-Shirazy ini mengandung unsur intrinsik yaitu: tema, penokohan/tokoh, alur, latar, sudut pandang, gaya bahasa, dan amanat. Tema yang dapat di deskripsikan dalam novel bumi cinta karya Habiburrahman El-Shirazy ini adalah kekuatan iman. Alur yang digunakan dalam novel bumi cinta karya Habiburrahman El-Shirazy ini menggunakan alur campuran. Tokoh dalam novel bumi cinta karya Habiburrahman El-Shirazy ini yaitu terdiri dari, tokoh utama: Ayyas, Yelena, dan Linor. Dan tokoh tambahan: Anastasia Palazzo, Devid, Bibi Margareta, dan Pak Joko. Latar dalam novel ini menggunakan latar tempat yaitu: kota Moskwa, bandara Sheremetyovo, Apartement tua dan lain lain. Sudut pandang yang digunakan yaitu sudut pandang orang ketiga karena pengarang menggunakan nama tokoh dan kata ia. Gaya bahasa yang digunakan berupa simile dan personifikasi. Dan amanat yang disampaikan pengarang yaitu, hendaklah kita sesama manusia saling tolong menolong dan saling menghargai walaupun berbeda agama dan bertawakallah jika mendapat musibah sebab Tuhan tidak menguji manusia di luar batas kemampuannya.

2. Novel Bumi Cinta karya Habiburrahman El-Shirazy ini terdapat nilai-nilai religius yaitu akidah, syariah, dan akhlak. Berupa ajaran tentang keimanan terhadap keesaan Allah SWT, serta peraturan tentang perilaku hidup manusia untuk mencapai keridhoan Allah.

Berdasarkan kesimpulan penelitian, maka peneliti merekomendasikan berupa saran-saran sebagai berikut:

1. Untuk meningkatkan pengetahuan terutama dalam bidang Bahasa dan Sastra Indonesia, serta menambah wawasan bagi penulis, dan khususnya bagi pembaca serta pecinta sastra.

2. Dalam proses belajar mengajar tentu penelitian ini dapat memberikan sumbangan aplikasi teori sastra dalam mengungkapkan nilai-nilai religius novel "Bumi Cinta Karya Habiburrahman El-Shirazy".

3. Bagi pembaca lainnya agar menjadikan penelitian ini sebagai bahan bacaan dan informasi sehingga bermanfaat dalam menkaji nilai-nilai religius sewaktu melaksakan penelitian.

4. Untuk lebih meningkatkan kualitas pengajar sastra, maka sudah saatnya kita mempelajari sastra agar menggali kekayaan yang terdapat dalam karya sastra.

\section{DAFTAR PUSTAKA}

Abdullah. (2007). Studi Akhlak dalam Perspektif Al-Quran. Jakarta: Amzah.

Ali, M. D. (2015). Pendidikan Agama Islam. Jakarta: Ra Grafindo Persada.

Anggraini. (2012). 1001 Ulasan Bahasa Indonesia SMA. Jakarta: Scientific Press.

Arikunto, S. (2013). Prosedur Penelitian Suatu Pendekatan Praktik. Edisi Revisi. Jakarta: PT Rineka Cipta.

Iskandar. (2009). Metologi Penelitian Kualitatif. Jakarta: Gaung Persada.

Ismawati, E. (2013). Pengajaran Sastra. Yogyakarta: Ombak. 
Kosasih, E. (2006). Cerdas Bahasa Indonesia Untuk SMA/MA Kelas XI. Jakarta: Erlangga.

Moleong, L. J. (2012). Metologi Penelitian Kualitatif. Bandung: Remaja Roslakarja.

Nurgiantoro. (2010). Teori Pengkajian Fiksi. Jakarta: Gajah Mada University Press.

Qomaria, N. (2018). Telaah Nilai Religius Dalam Kumpulan Puisi Surat Cinta dari Aceh Karya Syeh Khalil. Jurnal Pendidikan Agama Islam .

Rina, P. M. (2018). Nilai-nilai Religiusitas Dalam Novel Tasbih Cinta Di Langit Moskow Karya Indah El-Hafidz. Jurnal Pendidikan Agama Islam .

Shirazy, H. E. (2019). Novel Bumi Cinta. Jakarta: Republika Penerbit.

Siswanto. (2008). Karya Sastra Sebagai Dokumen Sosial Budaya. Yogyakarta.

Sugiyono. (2016). Metode Penelitian Pendidikan. Bandung: Alfabeta.

Sumardjo. (2013). Apresiasi Kesusastraan. Jakarta: Gramedia.

Tarigan, H. G. (2005). Membaca Sebagai Suatu Keterampilan Berbahasa. Bandung: Angkasa. 